\title{
National climate policy implications of mitigating embodied energy system emissions
}

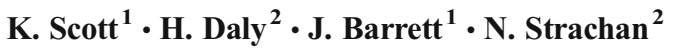

Received: 21 April 2015 / Accepted: 25 January 2016 / Published online: 19 February 2016

(C) The Author(s) 2016. This article is published with open access at Springerlink.com

\begin{abstract}
Rapid cuts in greenhouse gas emissions require an almost complete transformation of the energy system to low carbon energy sources. Little consideration has been given to the potential adverse carbon consequences associated with the technology transition. This paper considers the embodied emissions that will occur to replace the UK's fossil fuel-reliant energy supply with low carbon sources. The analysis generates a number of representative scenarios where emissions embodied in energy systems are integrated within current national climate and energy policy objectives. The embodied emissions associated with a new low carbon energy system are lower than the emissions reduction associated with the low carbon energy sources, confirming that there is a carbon return on investment. However, even if the UK reaches its 2050 territorial climate target, it is estimated that by 2050 an additional $200 \mathrm{Mt} \mathrm{CO}_{2}$ emissions are generated overseas (compared to $128 \mathrm{Mt}$ generated within the UK) in the production of imported fuels and infrastructure components. The cost-optimal model results suggest that more electrification would need to occur, supported by nuclear energy, mainly in replacement of natural gas to mitigate these emissions. However, due to a number of deployment barriers, other policy interventions along the energy supply chain are likely needed, which are discussed alongside the model results. There could be more emphasis on an absolute reduction in energy demand to reduce the scale of change needed in supplying energy; new business models oriented towards performance and not sales; and existing trade schemes and international effort-sharing frameworks could be extended.
\end{abstract}

Electronic supplementary material The online version of this article (doi:10.1007/s10584-016-1618-0) contains supplementary material, which is available to authorized users.

\section{K. Scott}

k.a.scott@leeds.ac.uk

1 Sustainability Research Institute, School of Earth and Environment, University of Leeds, Leeds LS2 9JT, UK

2 UCL Energy Institute, Central House, 14 Upper Woburn Place, London WC1H 0NN, UK 


\section{Introduction}

The fifth assessment report of the IPCC (Bruckner et al. 2014) outlines the requirements for a fundamental transformation to a low carbon energy system, without delay (Luderer et al. 2013). Despite reducing operational combustion emissions, the building of a new and capital intensive low carbon energy infrastructure will release GHG emissions associated with its material requirements (and the mining of), construction, distribution, maintenance and decommissioning (Giesekam et al. 2014, Müller et al. 2013), hereinafter referred to as embodied or indirect emissions. ${ }^{1}$ Increasingly material requirements are being imported from emerging and less developed countries (Kanemoto et al. 2014, Peters et al. 2011, Peters and Hertwich 2008). For example, China's surge in manufacturing since the 1990s has seen its exports dominate global trade flows, becoming the world's largest exporter of emissions (Kanemoto et al. 2014). Within an energy context, trends in exported emissions from China to the developed world are likely to continue as China now dominates the global low carbon technologies market (Liu and Goldstein 2013).

Little research has been conducted on the additional emissions generated by the infrastructure requirements of a global low carbon transition. Beyond theoretical (Suh 2004, Suh and Huppes 2005, Suh et al. 2004) and applied (Wiedmann et al. 2011, Acquaye et al. 2011, Crawford 2009) developments in life cycle impact assessments of energy technologies in the 2000s, there have been methodological contributions to improve our understanding of the environmental impacts of in-use and fixed capital stocks (e.g. buildings, infrastructure and products in which people derive a service) (Pauliuk and Müller 2014, Pauliuk et al. 2015), and more specifically in terms of energy pathways (Hertwich et al. 2014, Hammond et al. 2013, Igos et al. 2015). These have not however been applied to understanding implications for revising and setting national and international climate policies when emissions transfers are accounted for in the energy system. These studies have assessed the life cycle environmental consequences of low carbon energy policies, but have not internalised embodied emissions in the calculation of low carbon energy pathways. Such results can be compared with reduction targets but do not suggest how the energy pathways would change when including the embodied energy system emissions in mitigation targets.

The uncertainties, risks and barriers to a low carbon technology transition are quite widely documented, with the diffusion of technologies limited by institutional, behavioural and social constraints (Iyer et al. 2015, Bruckner et al. 2014). Industrialising countries look like they are emerging along the same fossil fuel path as those before them (Unruh and Carrillo-Hermosilla 2006), and governments that protect vested interests of powerful energy suppliers are likely to remain locked into carbon-intensive energy forms (Moe 2010). The current economics-driven policy approach has been shown to be incapable of delivering the type of low carbon investment required over the necessary timescales (Bolton and Foxon 2015).

The authors were the first to examine the emissions embodied in supplying energy by developing indirect emission factors for energy technologies and fuels with an input-output model and including them in an energy system model for the UK (Daly et al. 2015). In the analysis, indirect emissions in the generation of energy infrastructure and fuel processing are

\footnotetext{
${ }^{1}$ We define embodied emissions as the emissions generated along the energy supply chain up to the point of operation. This includes mining activities, fuel processing, electricity generation, emissions capture and fuel imports such as emissions from manufacturing mining drills, farming biomass, constructing power stations and manufacturing wind turbines
} 
reallocated from the source industry to the component of the UK energy system in which they are embodied, to be considered in a model of cost-optimal technology and fuel selection, and included in an emissions constraint aligned with the UK's 2050 emission target. The UK has a legally-binding target to reduce 1990 emissions by $80 \%$ by 2050 , and a series of interim carbon budgets aligned with this end-point. The study found that modelling only territorial emissions in the cost-optimal energy pathway lead to substantial international emissions transfers, and when required to mitigate embodied emissions generated abroad, the marginal cost of abatement more than doubled. Such outcomes are not just relevant for the UK, but contribute to the ongoing debate of accounting for traded emissions in international climate change negotiations. This paper builds upon that analysis and looks at the broader implications of accounting for emissions transfers in the UK energy system, both in terms of potential changes to the energy supply pathways and the UK's national energy and climate policy. This paper covers the following research questions:

1. How sizeable are the embodied emissions associated with the energy system in the UK required to deliver the 2050 emissions target?

2. What changes to energy sources and demand technologies are observed in a least-cost scenario, when emissions embodied in energy systems are considered in 2050 decarbonisation targets, and at what additional cost?

3. Is there evidence of alternative policy opportunities to reduce emissions embodied in an energy system beyond the technology solutions modelled, given the barriers and risks associated with low carbon energy technology solutions?

\section{Method}

Energy system optimisation models (ESOMs) are widely-used planning tools for regional, national and global energy systems, and are very highly detailed at the fuel and technology level. Well known examples include TIMES (Loulou et al. 2009), MESSAGE (Klaassen and Riahi 2007) and OSEMOSYS (Howells et al. 2011). This paper uses the UK TIMES model (UKTM) (built in the TIMES framework (Loulou et al. 2004)), which has had a strong underpinning role in UK energy and climate policy development (Ekins et al. 2011). It portrays the UK energy system from fuel extraction and trading, through energy conversion, such as the production of electricity, hydrogen and biofuels, to final energy demand (Daly et al. 2015). Emissions from industry, transport and services are added to the energy sector emissions to add up to UK territorial emissions. UKTM generates cost optimal scenarios of the future composition of the UK energy system, which meets energy service demands, taking into account assumptions regarding the evolution of final demands, technology costs and attributes and resource availability. Infrastructure requirements are defined as a cost to the system, representative of the physical flow of materials.

ESOMs have historically had a critical shortcoming: by counting emissions only at the point of combustion, they do not take into account the embodied impacts of energy pathways. By adding a value for indirect emissions, calculated using input-output analysis (Miller and Blair 2009), to each component of the energy system, supply chain emissions become a criterion for technology selection. We use our novel methodology described in Daly et al. (2015) to integrate embodied emissions to all activities upstream of energy supply. Embodied emissions are generated using a top-down global trade model (the input-output model employed in Wiedmann et al. (2011)), 
which traces the interactions between the UK energy sector and all other sectors within and outside UK territory. Indirect emissions are added to the supply-side energy sources and technologies, and not to demand-side technologies such as household boilers and cars. This is aligned with current climate policy which largely influences supply-side technologies, the focus of this paper.

This paragraph summarises the novel methodology we developed in Daly et al. (2015) (also see section S1 of the Supplementary Information), and the sections referenced here refer to sections in that article. Energy system technologies and fuel inputs in UKTM were aligned with an equivalent economic sector in the multi-region input-output model MRIO (section 2.3.). For each relevant MRIO sector, an indirect or embodied emissions factor expressed in $\mathrm{tCO}_{2}$ per £M was calculated for both the UK and a global average rest of world region (section 2.4). The embodied emissions were attributed to energy system technologies and traded fuels on the basis of installed capacity or fuel flow (section 2.4). The range of indirect emissions values for energy vectors are presented in Section 5 of Daly et al.'s supporting information. The volume of emissions reallocated from UK industry to the UK energy system as embodied emissions were subtracted from the UK industry emissions account (section 2.5.). Scenarios for future domestic and international emissions intensities and the import dependency of the UK economy were developed and run through UKTM (section 2.6.). Domestic embodied intensities were assumed to follow the same trajectory as the industry sector in UKTM. International embodied emissions intensities were assumed to decarbonise at the global average rate of $1 \%$ per year. Trade patterns are projected based on recent short-term trends. The paper also discussed some of the limitations and uncertainties of the approach which need further sensitivity analysis (section 4.2.), including country and sector aggregation, projection of global efficiency improvements and trade patterns, and the inclusion of emissions embodied in end-use technologies such as private vehicles household appliances.

\subsection{Emissions boundary allocation}

Our study focuses on energy supply as this dominates climate policy. Emissions in UKTM are constrained by UK cumulative carbon budgets which have been set to 2027 (HM Government 2011) and then a cumulative carbon budget which is equivalent to the same total amount of emissions as a linear emission reduction meeting the $80 \%$ target by 2050 , defined by the UK Committee on Climate Change as the most 'cost effective path' (CCC 2015a). To remain aligned with our previous scenarios in Daly et al. (2015) we describe the same 4 scenarios, however in the results comparisons are mainly drawn between S2 and S4. This is to understand how energy pathways would change when embodied emissions were included compared to the current approach where only combustion emissions are considered. The 4 scenarios are:

- S1. No target: the UK energy system is optimised on the basis of cost, with no emissions constraint. This represents a baseline scenario with no mitigation activities (however results focus on changes between S2-S4).

- S2. Target - direct only: combustion emissions in the UK energy system are optimised on the basis of cost, with total territorial $\mathrm{CO}_{2}$ emissions between 2010 and 2050 constrained to meet an $80 \%$ reduction target on 1990 levels by 2050, representative of current UK policy.

- S3. Target - Direct \& UK emissions: embodied energy system emissions from domestic industry are re-allocated to the energy system from the industry sector and included in the 
optimisation. As above, total territorial $\mathrm{CO}_{2}$ emissions between 2010 and 2050 are constrained to meet an $80 \%$ reduction target.

- S4. Target - All emissions: international emissions are allocated to the UK energy system component in which they are embodied and included in the optimisation process. Territorial and imported $\mathrm{CO}_{2}$ emissions minus emissions embodied in exports, between 2010 and 2050 , are constrained to meet the carbon budget imposed by the $80 \%$ territorial target.

Each scenario generates the cost optimal technology mix to meet a specified demand for around 50 energy services (e.g. car kilometres, lighting and industrial heating) in the UK with increasing emissions to be mitigated. Energy service demands over the period will grow at different rates according to official government projections, with most increasing (e.g. international aviation doubles in the period) and some decreasing (some industrial demands, bus and domestic navigation). The scenarios are indicative of the changes to conventional energy pathways that consider territorial emissions only. We do not consider a comprehensive set of possible future pathways, and instead isolate the impact of including traded emissions. Hence, all other variables are held constant in the model. UKTM includes all greenhouse gases in the reduction targets; however the model only considers $\mathrm{CO}_{2}$ in terms of energy sources and technology selection therefore the focus of the paper is $\mathrm{CO}_{2}$ only. This analysis focuses on emissions pathways from 2010 (the latest year modelled which is used to represent current levels) to 2050.

\section{Results}

UKTM produces cost-optimal adjustments to energy supply vectors and technologies when embodied emissions are included in the UK's carbon budgets. Whilst we analyse one modelling exercise, a model run in isolation does not provide a complete policy assessment. Cost-optimisation alone cannot guarantee the desired emissions target due to governance, societal and technology barriers and future uncertainties. Therefore, in the discussion we consider the evidence for alternative policy options to those modelled here.

\subsection{Embodied energy system emissions 2010-2050}

Figure 1 shows the change in UK territorial combustion emissions and the additional indirect emissions embodied in the UK energy system under the three scenarios from 2010 to 2050. In 2010 UK territorial emissions were $527 \mathrm{Mt} . \mathrm{CO}_{2}$ and an additional $115 \mathrm{Mt} . \mathrm{CO}_{2}$ was embodied in the energy system. $85 \%$ of the embodied emissions were emitted outside the UK.

Constraining territorial combustion emissions only in the 2050 emissions reduction target of $80 \%$ (S2 in Fig. 1), the current policy, reduces combustion emissions by $77 \%$ from 2010 to 2050. However overseas emissions more than double over the same time period, meaning that total emissions (including embodied emissions) are only reduced by around $50 \%$. Energy service demand over this time period has increased across most categories, trade is on an upward trend and production efficiencies in the rest of the world progress at the global average of $1 \%$ per year. As embodied energy system emissions originating in other UK industries (e.g. from the manufacture of renewable energy technologies) represent less than a $3 \%$ share of energy system emissions in 2010, declining even further by 2050, their inclusion in targets makes little difference to the results (S3). Only when embodied emissions 


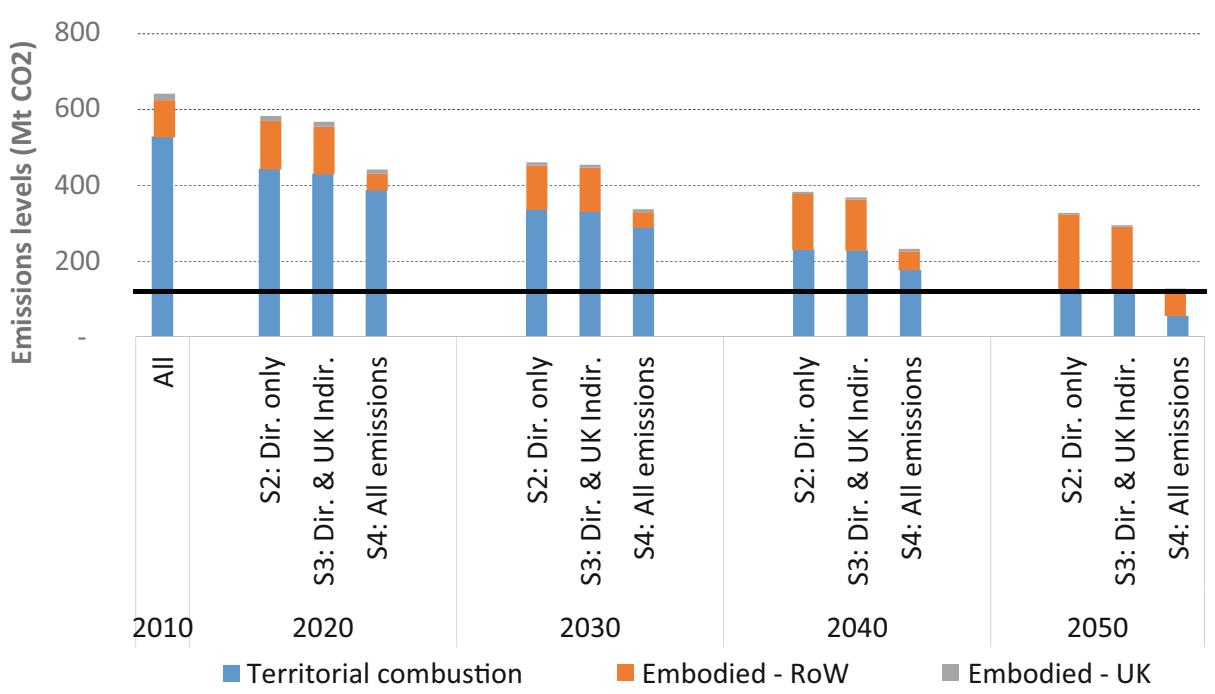

Fig. 1 Combustion and embodied emissions when increasing mitigation from UK energy system emissions to include embodied emissions in the UK 2050 climate target (black solid line $=80 \%$ target)

generated in industry overseas (to produce technology components imported to the UK) are considered in the cost-optimal energy pathway, and hence mitigated in the UK's carbon budgets, are we able to influence the $98 \mathrm{Mt} . \mathrm{CO}_{2}$ (18\% share) currently generated outside the UK. Results in the following sub-section therefore concentrate on the differences between S2 and S4. When mitigating for embodied emissions in the $80 \%$ reduction target (S4) by avoiding burden shifting abroad, UK combustion emissions need to reduce by almost $90 \%$ from 2010 to 2050 (in S2 they reduce $77 \%$ ).

Cumulatively, ${ }^{2}$ in meeting the domestic $80 \%$ emissions reduction (S2), 14Gt and 6Gt cumulative $\mathrm{CO}_{2}$ emissions are released in the UK and abroad respectively. $5 \mathrm{Gt}$ are prevented from entering the atmosphere if imported emissions are mitigated in the UK's end-point target, emitting nearly $15 \mathrm{Gt} \mathrm{CO}_{2}$. To put this into perspective, the latest figures from the IPCC suggest less than $1000 \mathrm{GtCO}_{2}$ can be emitted globally up to 2100 to have a $66 \%$ probability of limiting global warming to 2 degrees (Stocker et al. 2013). If national carbon budgets were apportioned based on current population the UK would have a $9 \mathrm{Gt}$ allowance, $40 \%$ under our best case scenario (S4). This is within the range suggested by Raupach et al. (2014), calculated to be between 7 and $12 \mathrm{Gt} \mathrm{CO}_{2}{ }^{3}$

\subsection{Energy system changes}

This sub-section describes changes to the energy sources, demand technologies and cost to the energy system when mitigating for embodied emissions. This is done by comparing two scenarios: imported emissions are included in the target (S4) compared to the territorial target (S2). The underlying dynamics of UKTM, such as technology and cost characteristics, remain

\footnotetext{
${ }^{2}$ The model is run at five year intervals and the results are interpolated between years and summed to calculate cumulative emissions.

${ }^{3}$ Raupach et al. estimate Europe has a carbon budget of 90 to $159 \mathrm{GT} \mathrm{CO}_{2}$ under three burden sharing principles. We estimate this to be in the region of 7 and 12 Gt for the UK given the UK's 2015 share of Europe's population to be $7.6 \%$.
} 
a strong determining factor with the addition of embodied emissions. Figure 2 shows the change in composition of UK primary energy consumption (PEC) in 2030 and 2050 between the two scenarios. Fossil fuel sources contribute $88 \%(8,565 \mathrm{PJ})$ to PEC in 2010 reducing to $53 \%(5,137 \mathrm{PJ})$ and $36 \%(3,315 \mathrm{PJ})$ in 2050 in S2 and S4 respectively. To meet the territorial target (S2) natural gas retains over a third of the share (3,543PJ), yet when embodied emissions are included (S4) the share drops to a quarter $(2,201 \mathrm{PJ})$. The share of renewables increases to $6 \%$ in both scenarios (475-478PJ) in the medium term (2030) and then reduces to $1 \%$ in the longer-term (2050) (122-133PJ). The share of biofuels steadily rises in both scenarios to make up over a fifth of energy consumption. The most notable difference is the increase of nuclear energy from $6 \%$ (562PJ) in 2010 to $24 \%$ (2,377PJ) and $39 \%$ (3,610PJ) by 2050 in S2 and S4 respectively. In order to compensate for the stricter carbon budgets, the trends in technologies selected tend to remain similar between S2 and S4, yet the deployment of lower carbon technologies is greater in S4 when mitigating embodied emissions alongside operational ones. Under the technology assumptions for this scenario set, UKTM generally projects the longterm (levelised) costs of nuclear lower than (intermittent) renewables plus back up, with and without embodied emissions. Sunk infrastructure costs are a relatively low share of the overall costs of electricity technology options and allows interim (in this case renewable) technologies to be invested in and then not replaced when first generation units reach the end of their working life.

Primary energy consumed (the composition of which is shown in Fig. 2) is sourced from domestic energy production and imported fuels. The UK also exports fuels for consumption overseas. Figure 3 shows the decadal change from 2010 to 2050 in territorial primary energy production (PEP), the trade balance of fuels (i.e. imports minus exports), primary energy consumption (PEC) and final energy consumption (FEC) between S4 and S2 by energy source. This illustrates the change in energy production and trading in fuels that would cost effectively meet the emissions reduction required should the UK decide to mitigate the indirect energy system emissions. Pre-2025, the reduction in UK oil production outweighs the increase

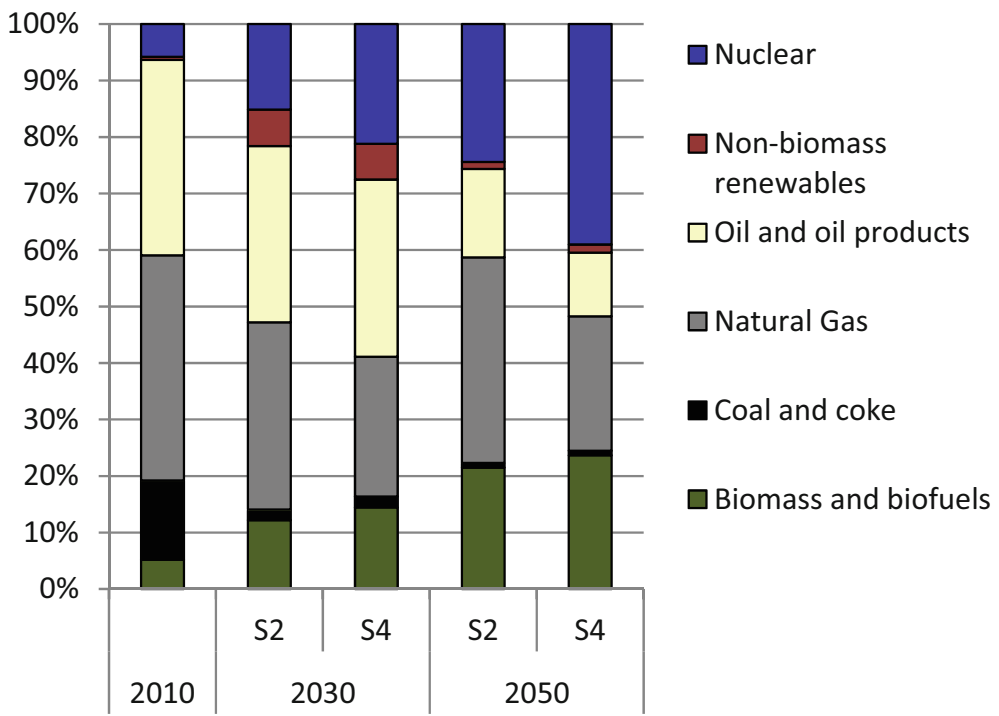

Fig. 2 Composition of UK primary energy consumption in 2030 and 2050 compared to 2010 for S2 and S4 
in gas produced. Despite achieving a cumulative reduction in PEP between 2010 and 2050, post-2025, PEP starts on an upward trajectory as natural gas production becomes greater than the reduction in oil being produced. By 2050, shale gas is responsible for the majority of increases in PEP. UK fuel trading shows the opposite trend. Cumulatively, the UK imports more fuels than it exports over the time period, but net imports are on a downward trend from 2025. Until 2030, the UK continues to import more oil than it exports, followed by an increase in net imports of uranium in the 2030s. However, post-2030 net exports of UK natural gas grow, and grow at a rate greater than the imports of uranium. Whilst production of gas in the UK increases (almost an additional 18,000 PJ is produced between 2010 and 2050), it proves cost-effective to export, and therefore primary consumption reduces. The reduction in natural gas is compensated mainly by an increase in imports of uranium (nearly 23,000 PJ) and biomass (nearly $5000 \mathrm{PJ}$ ), which have lower life cycle emissions. Embodied emissions results in the overall emission budget under S4 being tighter, and hence, the intertemporal UKTM reduces domestic oil in the near term and overall oil use in the aggregate. The reduced demand for gas in the UK and the equivalent embodied emissions for domestic and international gas combine to allow the UK to export more. UK oil and gas resource is generally not coproductive whilst imports of these fuels occur via separate international markets.

Figure 3 also compares the impact of mitigating indirect emissions on final energy consumption (FEC). FEC by intermediate (electricity and hydrogen) and end-use (residential, transport, industry and services) sectors are presented in Fig. 4. The reduction in FEC is marginal from 2010 to 2050, except between 2030 and 2040 where annual final energy consumption reduces to around 600 PJ. This reduction is achieved in the residential and transport sectors, with energy consumption of industry and services changing very little. With the exception of transport, electrification happens across all sectors, and hydrogen displaces fossil fuel consumption in transport. Electrification is supported by the increase in imported nuclear fuels, which displaces final demand for natural gas, yet hydrogen production in turn consumes natural gas.
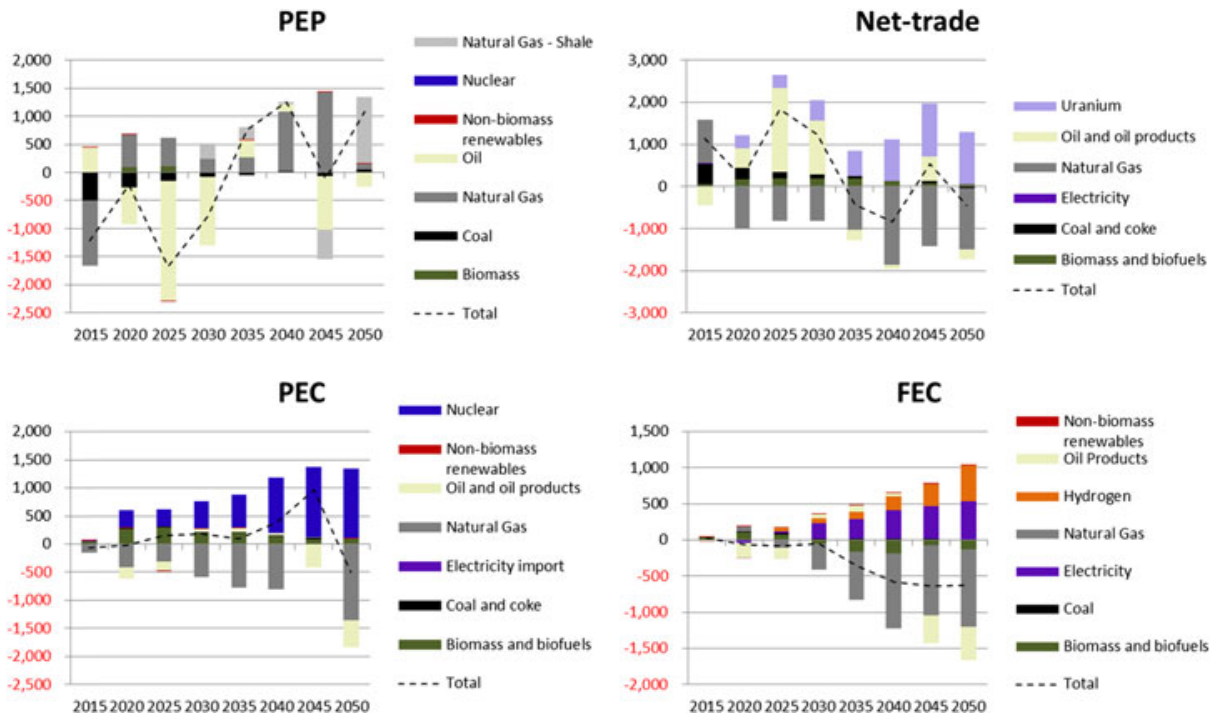

Fig. 3 Time series change in PEP, Net-trade, PEC and FEC between 2010 and 2050 when mitigating for embodied emissions in the UK's 2050 climate target (i.e. Scenario 4 - Scenario 2) 

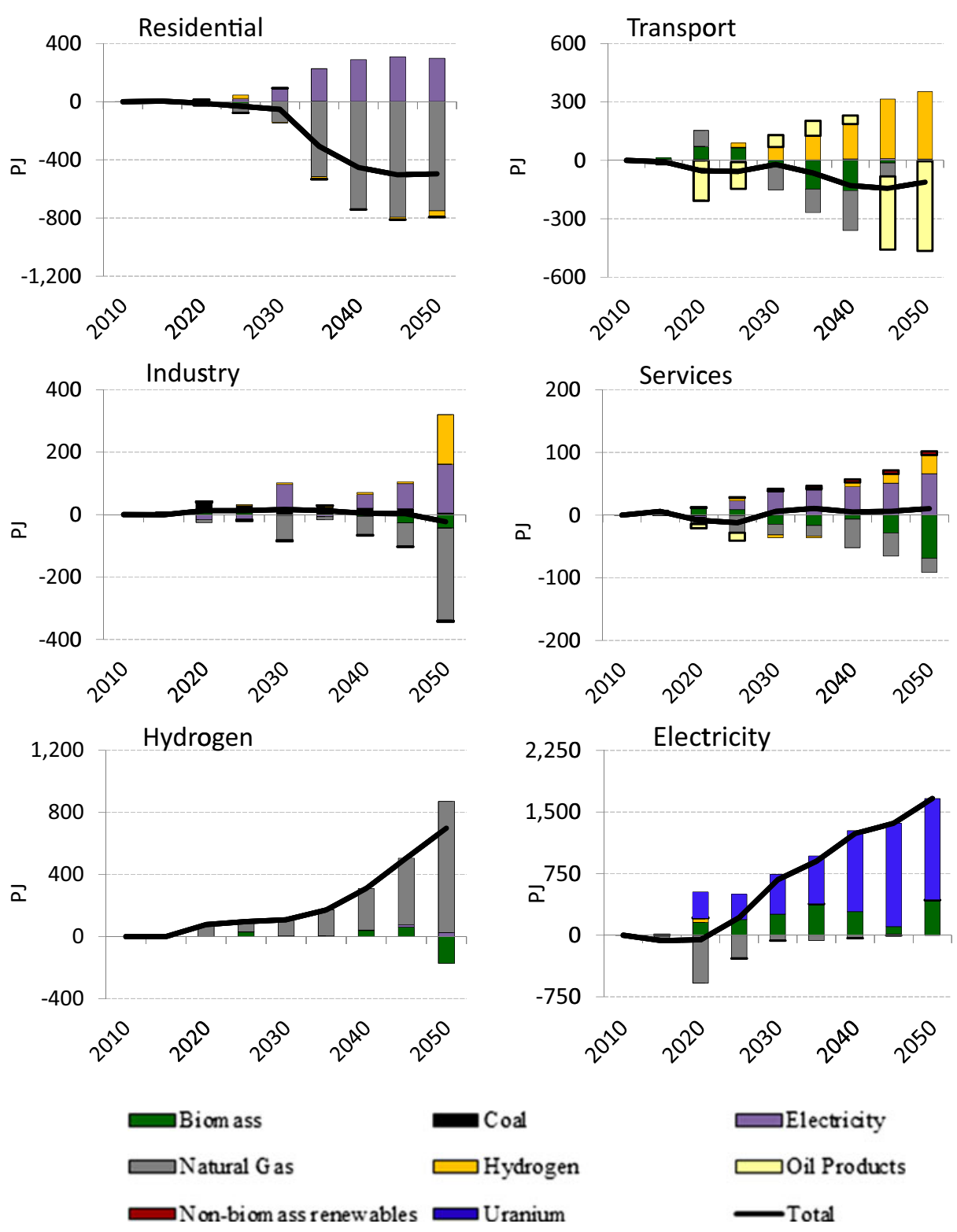

Fig. 4 Changes to FEC by end-use sector and intermediate energy consumption by electricity and hydrogen when mitigating for embodied emissions (i.e. Scenario 4 - Scenario 2)

As is clear from the results, UKTM favours particular technologies and fuel pathways. Nuclear becomes a dominant fuel source by 2050 in both scenarios, mainly displacing natural gas. The same climate outcome could be met by renewables or biofuels, but under the assumptions of UKTM in this study surrounding the cost and technical features of different technologies and fuel sources, nuclear is the lowest cost low-carbon option, with and without accounting for embodied emissions. Similarly, less importing of natural gas is favoured over less consumption and more domestic production (Fig. 3). A feature of technology selection in 
least-cost ESOMs, like all linear optimisation models, is "penny switching behaviour", where a small change in costs can lead to sudden changes in results. Given the uncertain nature of future costs and policy and social constraints, and given that investment behaviours do not conform to this penny-switching, these results should not be interpreted as a forecast of the future but rather a set of informed scenarios, sensitive to input assumptions.

Increasing the UK's reduction effort to mitigate its indirect energy system emissions comes at an additional cost. Table 1 describes the annual cost increase (at 5 year intervals) and cumulative change in energy system cost from 2010 to 2050 (undiscounted $^{4}$ ) when mitigating for indirect emissions (S4), compared to S2 (achieving the territorial target). Overall this increases the cost of S2 by $3.7 \%$ - $£ 682.5$ billion from 2010 to 2050 . Generally, higher costs will be faced in the future and by 2050 it is estimated that mitigating the additional emissions increases costs by around $5 \%$ of what they are estimated to be if they were not included in the target. However, these costs do not consider the reduced costs of adapting to climate change and therefore offer a comparability of mitigation costs between scenarios, but not the overall cost to the economy.

\section{Policy discussion}

While low-carbon technologies and fuels can deliver a substantial reduction in emissions, even taking embodied emissions into account, there are adverse effects on global emissions. The UK increasingly imports goods and services from countries outside the EU (Committee on Climate Change 2013). When comparing the embodied emissions of energy infrastructure from equivalent productive sectors in the UK and overseas, we found overseas technologies to have been produced on average more carbon intensively than in the UK (see section 5 of the supporting information in Daly et al. (2015)). This paper's analysis shows that emissions generated outside the UK to meet its energy infrastructure demands are set to increase through to 2050 and could be in the region of $60 \%$ higher than UK direct emissions. This poses a policy problem as only a few countries, representing $15 \%$ of global emissions, are currently being held to legally-binding emissions reduction targets (Grubb 2013).

In modelling the UK's mitigation of emissions embodied in its energy supply in the $80 \%$ end-point target, the overall cost of the low carbon transition increases by $3.7 \%$. The most substantial change in the model is an increase in nuclear capacity, largely to support electrification of final energy consumption. Uranium and biomass in the low carbon energy system pathway is increased from $24 \%$ and $21 \%$ to $39 \%$ and $24 \%$ respectively. This increase is met by imports, and the UK exports more gas to be consumed abroad, falling outside the UK's emission boundary. While under these modelling scenarios renewable energy does not play a major role, ESOMs are not forecasting tools and have a limited capability for incorporating uncertainties in long-term costs and constraints, and so should not be used as a single tool for planning future policies.

If the UK was to take responsibility for the additional emissions generated abroad, adjustments to budgets would need to be made to ensure the same intended carbon outcome (i.e. an $80 \%$ reduction in emissions) if the accounting system was to remain as is. However, recent reductions in the UK's territorial emissions, reaching $8 \%$ in 2014 despite strong economic growth, have not been the result of planned climate policy. Many of the reductions

\footnotetext{
${ }^{4}$ We are comparing the costs between two scenarios therefore the difference would be the same whether costs were discounted or not
} 
Table 1 Additional annual undiscounted energy system costs and percentage increase at 5 year intervals and cumulatively when mitigating for embodied emissions (i.e. increased cost of S4 compared to S2)

\begin{tabular}{llllllllll}
\hline Year & 2015 & 2020 & 2025 & 2030 & 2035 & 2040 & 2045 & 2050 & $2010-2050$ \\
\hline Absolute cost increase (£M) & 2630 & 10,492 & 16,953 & 17,474 & 17,581 & 21,980 & 30,422 & 30,910 & 682,547 \\
Percentage change (\%) & 0.8 & 2.7 & 4.0 & 3.7 & 3.5 & 4.1 & 5.4 & 5.2 & 3.7 \\
\hline
\end{tabular}

from building, industry and power emissions reflect one off changes and uncertain factors rather than replicable ongoing trends, e.g. a mild winter (CCC 2015b). The $\mathrm{CCC}$ also perceives a gap between existing and foreseeable climate policies and future UK carbon budgets. Given this and the widespread barriers and risks associated with low carbon energy technology solutions (documented in Bruckner et al. 2014) there are alternatives that would ease the dependency on unprecedented rapid deployment rates; publicly debated technologies (particularly nuclear); and rising costs from greater reduction requirements; whilst increasing the scope to reduce imported emissions. Taking a supply-chain or embodied perspective of energy brings other policy opportunities into view. We identify the evidence for these under four broad categories: demand, business models, trading schemes and international effort-sharing:

- Demand response - Emissions could be avoided by achieving an absolute reduction in energy demand. Anderson et al. (2008) suggest that the neglect of energy demand reduction is eroding the UK's ability to play its part in maintaining a two degree future. Although demand reduction initiatives have not been modelled in this paper they have been shown to be cost effective and complementary to technology led decarbonisation (Strachan et al. 2008) and have the scope to reduce both domestic and imported emissions through reducing demand for materials, goods and services that embody energy (Barrett and Scott 2012). Emerging evidence shows the potential for material and product consumption to contribute sizeable reductions in emissions (Barrett and Scott 2012, Allwood et al. 2010, Allwood et al. 2011).

- Business response - Alternative business models whereby product sales are replaced with a service or leasing contract can decouple resource needs from energy demand (Roelich et al. 2015, Steinberger et al. 2009, Hannon et al. 2013). Energy Service Companies can shift away from selling metered quantities of energy towards selling energy services such as thermal comfort and illumination (Sorrell 2007). Profits are incentivised by improvements in energy efficiency instead of selling more units. In addition energy using appliances can be leased whereby the provider retains ownership and is responsible for its general maintenance and the consumer has possession and use of the asset for a prefixed payment period. In this situation energy efficiency is shown to play a bigger role in replacement decisions, and remanufacturing is increased (Roelich et al. 2015).

- Trade response - Currently the EU Emissions Trading Scheme compensates or exempts carbon-intensive industries perceived as being at risk of competition from cheaper energy costs elsewhere (Martin et al. 2014). Extending the EU Emissions Trading Scheme (ETS) to account for the emissions embodied in trade could increase the scope for reductions whilst reducing competitive worries (Carbon Trust 2006, Carbon Trust 2008). For example international agreements could be set up which incorporate the major competitors in a particular sector whereby the carbon costs are reflected across all producers' sales products. 
Alternatively border tax adjustments can be implemented on energy-intensive imports to close the cost differentiation (Vivid Economics with Ecofys 2013).

- International response - Effort-sharing frameworks could help address distributional issues between industrialised and developing countries (Edenhofer et al. 2014). Interregional instruments such as the Clean Development Mechanism and Joint Implementation involve the transfer of technologies, renewable energy implementation projects or the financing of abatement projects overseas, for which the UK can receive carbon credits. These can currently be used to offset excessive emissions generation in the EU ETS, and have been shown to offer cheaper mitigation opportunities as they have less installed abatement measures (Harris and Symons 2012).

These four policy options would require additional modelling work to assess their overall impacts on the role of embodied emissions, but they do address the problem and present an alternative from a purely technological driven solution.

\section{Conclusions}

This research has focused on novel linked modelling, using the UK as a case study, for integrating embodied emissions (both domestic and international) within energy supply, given its prominence in energy and climate policy. Even when the embodied emissions of a new low carbon energy infrastructure are left unabated, low carbon technologies can deliver a substantial reduction in emissions. However, changes in the UK energy system generate additional emissions outside the UK and in many cases the EU and their emissions reductions targets. This is problematic because globally legally-binding emissions reductions targets only capture $15 \%$ of emissions. If imported emissions remain excluded from climate targets, this figure is less likely to change. The UK could extend the scope of its own carbon budgets to ensure it achieves the same intended outcome, a reduction in its emissions by $80 \%$, by increasing the speed of low carbon technology roll-out or further exploration of other consumption-side/ energy demand factors.

In this paper, embodied emissions have been considered up to the point of supply and future research could consider embodied emissions within the same framework for enduse services such as boilers, electrical appliances and vehicles, all of which consume and embody energy. These will both increase emissions allocated to the energy system modelled, currently sitting in the industry sector and country in which they are produced, and provide opportunities for emissions reductions through behavioural changes. Exploiting more demand reduction, service delivery and international opportunities could deliver energy and emissions reductions at a reduced cost, and need to be assessed in a holistic framework.

Acknowledgments We thank Julia Steinberger and the anonymous reviewers for their constructive feedback. The research was developed under UKERC (NE/G007748/1), wholeSEM ( EP/K039326/1) and CIE-MAP $(\mathrm{EP} / \mathrm{K} 011774 / 1)$.

Open Access This article is distributed under the terms of the Creative Commons Attribution 4.0 International License (http://creativecommons.org/licenses/by/4.0/), which permits unrestricted use, distribution, and reproduction in any medium, provided you give appropriate credit to the original author(s) and the source, provide a link to the Creative Commons license, and indicate if changes were made. 


\section{References}

Acquaye AA, Wiedmann T, Feng K, Crawford RH, Barrett J, Kuylenstierna J, Duffy AP, Koh SCL, McqueenMason S (2011) Identification of 'carbon hot-spots' and quantification of GHG intensities in the biodiesel supply chain using hybrid LCA and structural path analysis. Environ Sci Technol 45:2471-2478

Allwood JM, Cullen JM, Milford RL (2010) Options for achieving a $50 \%$ cut in industrial carbon emissions by 2050. Environ Sci Technol 44:1888-1894

Allwood JM, Ashby MF, Gutowski TG, Worrell E (2011) Material efficiency: a white paper. Resour Conserv Recycl 55:362-381

Anderson K, Bows A, Mander S (2008) From long-term targets to cumulative emission pathways: reframing UK climate policy. Energ Policy 36:3714-3722

Barrett J, Scott K (2012) Link between climate change and resource efficiency. Glob Environ Chang 22:299-307

Bolton R, Foxon TJ (2015) A socio-technical perspective on low carbon investment challenges - insights for UK energy policy. Environmental Innovation and Societal Transitions 14:165-181

Bruckner T, Bashmakov IA, Mulugetta Y, Chum H, De la Vega Navarro A, Edmonds J, \& Al E (2014). Energy Systems. In: Edenhofer O, Pichs-Madruga R, Sokona Y, Farahani E, Kadner S, Seyboth K, et al. (ed.) Climate Change 2014: Mitigation of Climate Change. Contribution of Working Group III to the Fifth Assessment Report of the Intergovernmental Panel on Climate Change. Cambridge: Cambridge University Press

Carbon Trust (2006). Allocation and competitiveness in the EU emissions trading scheme - options for phase II and beyond. UK

Carbon Trust (2008). Cutting carbon in europe - the 2020 plans and the future of the EU ETS. UK

CCC (2015a). Meeting carbon budgets - progress in reducing the UK's emissions: 2015 report to parliament. London

CCC (2015b). Reducing emissions and preparing for climate change: 2015 progress report to parliament London, UK

Committee on climate change (2013). Reducing the UK's carbon footprint. London

Crawford RH (2009) Life cycle energy and greenhouse emissions analysis of wind turbines and the effect of size on energy yield. Renew Sust Energ Rev 13:2653-2660

Daly HE, Scott K, Strachan N, Barrett JR (2015) The indirect CO2 emission implications of energy system pathways: linking IO and TIMES models for the UK. Environ Sci Technol 49(17):10701-10709

Edenhofer O, Pichs-Madruga R, Sokona Y, Farahani E, Kadner S, Seyboth K, Adler A, Baum I, Brunner S, Eickemeier P, Kriemann B, Savolainen J, Schlömer S, Von Stechow CTZ, Minx JC (2014) Climate change 2014: mitigation of climate change. Contribution of Working Group III to the Fifth Assessment Report of the Intergovernmental Panel on Climate Change Cambridge University Press, Cambridge

Ekins P, Anandarajah G, Strachan N (2011) Towards a low-carbon economy: scenarios and policies for the UK. Clim Pol 11:865-882

Giesekam J, Barrett J, Taylor P, Owen A (2014) The greenhouse gas emissions and mitigation options for materials used in UK construction. Energy and Buildings 78:202-214

Grubb M (2013) Doha's dawn? Clim Pol 13:281-284

Hammond GP, Howard HR, Jones CI (2013) The energy and environmental implications of UK more electric transition pathways: A whole systems perspective. Energ Policy 52:103-116

Hannon MJ, Foxon TJ, Gale WF (2013) The co-evolutionary relationship between energy service companies and the UK energy system: implications for a low-carbon transition. Energ Policy 61:1031-1045

Harris PG, Symons J (2012) Norm conflict in climate governance: greenhouse gas accounting and the problem of consumption. Global Environmental Politics 13:9-29

Hertwich EG, Gibon T, Bouman EA, Arvesen A, Suh S, Heath GA, Bergesen JD, Ramirez A, Vega MI \& Shi L (2014). Integrated life-cycle assessment of electricity-supply scenarios confirms global environmental benefit of low-carbon technologies. Proceedings of the National Academy of Sciences

HM Government (2011). The carbon plan: delivering our low carbon future. London

Howells M, Rogner H, Strachan N, Heaps C, Huntington H, Kypreos S, Hughes A, Silveira S, Decarolis J, Bazillian M, Roehrl A (2011) OSeMOSYS: the open source energy modeling system an introduction to its ethos, structure and development. Energ Policy 39:5850-5870

Igos E, Rugani B, Rege S, Benetto E, Drouet L, Zachary DS (2015) Combination of equilibrium models and hybrid life cycle-input-output analysis to predict the environmental impacts of energy policy scenarios. Appl Energy 145:234-245

Iyer G, Hultman N, Eom J, Mcjeon H, Patel P, Clarke L (2015) Diffusion of low-carbon technologies and the feasibility of long-term climate targets. Technol Forecast Soc Chang 90:103-118

Kanemoto K, Moran D, Lenzen M, Geschke A (2014) International trade undermines national emission reduction targets: new evidence from air pollution. Glob Environ Chang 24:52-59

Klaassen G, Riahi K (2007) Internalizing externalities of electricity generation: an analysis with MESSAGEMACRO. Energ Policy 35:815-827 
Liu J, Goldstein D (2013) Understanding China's renewable energy technology exports. Energ Policy 52:417-428

Loulou, R., Goldstein, G. \& Noble, K. (2004). Documentation for the MARKAL family of models. Energy Technology Systems Analysis Programme

Loulou R, Labriet M, Kanudia A (2009) Deterministic and stochastic analysis of alternative climate targets under differentiated cooperation regimes. Energy Economics 31:S131-S143

Luderer G, Bertram C, Calvin K, De Cian E \& Kriegler E (2013). Implications of weak near-term climate policies on long-term mitigation pathways. Clim Chang, 1-14

Martin R, Muuls M, De Preux LB, Wagner UJ (2014) On the empirical content of carbon leakage criteria in the EU emissions trading scheme. Ecol Econ 105:78-88

Miller RE, Blair PD (2009) Input-output analysis: foundations and extensions. Cambridge University Press, Cambridge

Moe E (2010) Energy, industry and politics: energy, vested interests, and long-term economic growth and development. Energy 35:1730-1740

Müller DB, Liu G, Løvik AN, Modaresi R, Pauliuk S, Steinhoff FS, Brattebø H (2013) Carbon emissions of infrastructure development. Environ Sci Technol 47:11739-11746

Pauliuk S, Müller DB (2014) The role of in-use stocks in the social metabolism and in climate change mitigation. Glob Environ Chang 24:132-142

Pauliuk S, Wood R, Hertwich EG (2015) Dynamic models of fixed capital stocks and their application in industrial ecology. J Ind Ecol 19:104-116

Peters GP, Hertwich EG (2008) CO2 embodied in international trade with implications for global climate policy. Environ Sci Technol 42:1401-1407

Peters GP, Minx JC, Weber CL, Edenhoffer O (2011) Growth in emission transfers via international trade from 1990 to 2008. PNAS 108:8903-8908

Raupach MR, Davis SJ, Peters GP, Andrew RM, Canadell JG, Ciais P, Friedlingstein P, Jotzo F, Van Vuuren DP, Le Quere C (2014) Sharing a quota on cumulative carbon emissions. Nat Clim Chang 4:873-879

Roelich K, Knoeri C, Steinberger JK, Varga L, Blythe PT, Butler D, Gupta R, Harrison GP, Martin C, Purnell P (2015) Towards resource-efficient and service-oriented integrated infrastructure operation. Technol Forecast Soc Chang 92:40-52

Sorrell S (2007) The economics of energy service contracts. Energ Policy 35:507-521

Steinberger JK, Van Niel J, Bourg D (2009) Profiting from negawatts: reducing absolute consumption and emissions through a performance-based energy economy. Energ Policy 37:361-370

Stocker TF, Qin D, Plattner G-K, Tignor M, Allen SK, Boschung J, Nauels A, Xia Y, Bex V, Midgley PM (2013) Climate change 2013: the physical science basis. Contribution of working group I to the fifth assessment report of the intergovernmental panel on climate change. Cambridge University Press, Cambridge, p. 1535

Strachan N, Foxon T, Fujino J (2008) Policy implications from the low-carbon society (LCS) modelling project. Clim Pol 8:17-29

Suh S (2004) Functions, commodities and environmental impacts in an ecological-economic model. Ecol Econ 48:451-467

Suh S, Huppes G (2005) Methods for life cycle inventory of a product. J Clean Prod 13:687-697

Suh S, Lenzen M, Treloar GJ, Hondo H, Horvath A, Huppes G, Jolliet O, Klann U, Krewitt W, Moriguchi Y, Munksgaard J, Norris G (2004) System boundary selection in life-cycle inventories using hybrid approaches. Environ Sci Technol 38:657-664

Unruh GC, Carrillo-Hermosilla J (2006) Globalizing carbon lock-in. Energ Policy 34:1185-1197

Vivid economics with ecofys (2013). Carbon leakage prospects under Phase III of the EU ETS, report prepared for DECC. UK

Wiedmann T, Suh S, Feng K, Lenzen M, Acquaye A, Scott K, Barrett J (2011) Application of hybrid life cycle approaches to emerging energy technologies - the case of wind power in the UK. Environ Sci Technol 45: 5900-5907 